\title{
The world's resources and the distribution of mankind
}

\section{Professor H. N. Dickson M.A., D.Sc.}

To cite this article: Professor H. N. Dickson M.A., D.Sc. (1913) The world's resources and the distribution of mankind, Scottish Geographical Magazine, 29:10, 509-523, DOI: $10.1080 / 00369221308734105$

To link to this article: http://dx.doi.org/10.1080/00369221308734105

册 Published online: 28 Jun 2010.

Submit your article to this journal $[\pi$

Џll Article views: 4

Q View related articles $๘$ 


\title{
THE SCOTTISH
}

\section{GEOGRA PHICAL}

\author{
MAGAZINE.
}

\section{THE WORLD'S RESOURCES AND THE DISTRIBUTION OF MANKIND. ${ }^{1}$}

By Professor H. N. Dickson, M.A., D.Sc.

SINCE the last meeting of this Section the tragic fate of Captain Scott's party, after its successful journey to the South Pole, has become known; and our hopes of welcoming a great leader, after great achievement, have been disappointed. There is no need to repeat here the narrative of events, or to dwell upon the lessons afforded by the skill, and resource, and heroic persistence, which endured to the end. All these have been, or will be, placed upon permanent record. But it is right that we should add our word of appreciation, and proffer our sympathy to those who have suffered loss. It is for us also to take note that this last of the great Antarctic expeditions has not merely reached the Pole, as another has done, but has added, to an extent that few successful exploratory undertakings have ever been able to do, to the sum of scientific geographical knowledge. As the materials secured are worked out it will, I believe, become more and more apparent that few of the physical and biological sciences have not received contributions, and important contributions, of new facts; and also that problems concerning the distribution of the different groups of phenomena and their action and reaction upon one another-the problems which are specially within the domain of the geographer-have not merely been extended in their scope but have been helped towards their solution.

The reaching of the two Poles of the earth brings to a close a long and brilliant chapter in the story of geographical exploration. There is still before us'a vista of arduous research in geograph ${ }$, bewildering almost in its extent, in such a degree indeed that "the scope of geography"

1 Presidential Address to Section E (Geography), at the Birmingham Meeting of the British Association, September 1913.

voL XXIX. 
is in itself a subject of perennial interest But the days of great pioneer discoveries in topography have definitely drawn to their close. We know the size and shape of the earth, at least to a first approximation, and as the map fills up we know that there can be no new continents and no new oceans to discover, although all are still, in a sense, to conquer. Looking back, we find that the qualities of human enterprise and endurance have shown no change; we need no list of names to prove that they were alike in the days of the earliest explorations, of the discovery of the New World or of the sea route to India, of the "Principall Navigations," or of this final attainment of the Poles. The love of adventure and the gifts of courage and endurance have remained the same : the order of discovery has been determined rather by the play of imagination upon accumulated knowledge, suggesting new methods and developing appropriate inventions. Men have dared to do risky things with inadequate appliances, and in doing so have shown how the appliances may be improved and how new enterprises may become possible as well as old ones easier and safer. As we come to the end of these "great explorations," and are restricted more and more to investigations of a less striking sort, it is well to remember that in geography, as in all other sciences, research continues to make as great demands as ever upon those same qualities, and that the same recognition is due to those who continue in patient labour.

When we look into the future of geographical study, it appears that. for some time to come we shall still be largely dependent upon work similar to that of the pioneer type to which I have referred, the work of perfecting the geographer's principal weapon, the map. There are many parts of the world about which we can say little except that we know they exist; even the topographical map, or the material for making it, is wanting; and of only a few regions are there really adequate distributional maps of any kind. These matters have been brought before this Section and discussed very fully in recent years, so I need say no more about them, except perhaps to express the hope and belief that the production of topographical maps of difficult regions may soon be greatly facilitated and accelerated with the help of the new art of flying.

I wish to-day rather to ask your attention for a short time to a phase of pioneer exploration which has excited an increasing amount of interest. in recent years. Civilised man is, or ought to be, beginning to realise that in reducing more and more of the available surface of the earth to what he considers a habitable condition he is making so much progress, and making it so rapidly, that the problem of finding suitable accommodation for his increasing numbers must become urgent in a few generations. We are getting into the position of the merchant whose trade is constantly expanding and who foresees that his premises will shortly be too small for him. In our case removal to more commodious premises elsewhere seems impossible-we are not likely to find a means of migrating to another planet-so we are driven to consider means of rebuilding on the old site, and so making the best of what we have, that our business may not suffer.

In the type of civilisation with which we are most familiar there are two fundamental elements-supplies of food energy, and supplies of 
mechanical energy. Since at present, partly because of geographical conditions, these do not necessarily (or even in general) occur together, there is a third essential factor, the line of transport. It may be of interest to glance, in the cursory manner which is possible upon such occasions, at some geographical points concerning each of these factors, and to hazard some speculations as to the probable course of events in the future.

In his Presidential Address to the British Association at its meeting at Bristol in 1898, Sir William Crookes gave some valuable estimates of the world's supply of wheat, which, as he pointed out, is "the most sustaining food-grain of the great Caucasian race." Founding upon these estimates, he made a forecast of the relations between the probable rates of increase of supply and demand, and concluded that "Should all the wheat-growing countries add to their (producing) area to the utmost capacity, on the most careful calculation the yield would give us only an addition of some 100,000,000 acres, supplying, at the average worldyield of $12 \cdot 7$ bushels to the acre, 1,270,000,000 bushels, just enough to supply the increase of population among bread-eaters till the year 1931." The president then added, "Thirty years is but a day in the life of a nation. Those present who may attend the meeting of the British Association thirty years hence will judge how far my forecasts are justified."

Half the allotted span has now elapsed, and it may bo useful to inquire how things are going. Fortunately this can be easily done, up to a certain point at any rate, by reference to a paper published recently by Dr. J. F. Unstead, ${ }^{1}$ in which comparisons are given for the decades 1881 90, 1891-1900, and 1901-10. Dr. Unstead shows that the total wheat harvest for the world may be estimated at 2258 million bushels for the first of these periods, 2575 million for the second, and 3233 million for the third, increases of 14 per cent. and 25 per cent. respectively. Ho points out that the increases were due " mainly to an increased acreage," the areas being 192, 211, and 242 million acres, but also "to some extent (about 8 per cent.) to an increased average yield per acre, for while in the first two periods this was 12 bushels, in the third period it rose to 13 bushels per acre."

If we take the period 1891-1900, as nearly corresponding to Sir William Crookes' initial date, we find that the succeeding period shows an increase of 658 million bushels, or about half the estimated increase required by 1931 , and that attained chiefly by "increased acreage."

But signs are not wanting that increase in this way will not go on indefinitely. We note (also from Dr. Unstead's paper) that in the two later periods the percentage of total wheat produced which was exported from the United States fell from 32 to 19, the yield per acre showing an increase meanwhile to 14 bushels. In the Russian Empire the percentage fell from 26 to 23 , and only in the youngest of the new countries-Canada, Australia, and the Argentine-do we find large proportional increases. Again, it is significant that in the United Kingdom; which is, and always has been, the most sensitive of all wheat-producing 
countries to variations in the floating supply, the rate of falling-off of home production shows marked if irregular diminution.

Looking at it in another way, we find (still from Dr. Unstead's figures) that the total amount sent out by the great exporting countries averaged, in 1881-90 295 million bushels, 1891-1900 402 million, 1901-10 532 million. These quantities represent respectively $13 \cdot 0,15 \cdot 6$, and 16.1 per cent. of the total production, and it would appear that the percentage available for export from these regions is, for the time at least, approaching its limit, i.e. that only about one-sixth of the wheat produced is available from surpluses in the regions of production for making good deficiencies elsewhere.

There is, on the other hand, abundant evidence that improved agriculture is beginning to raise the yield per acre over a large part of the producing area. Between the periods $1881-90$ and 1901-10 the average in the United States rose from 12 to 14 bushels; in Russia from 8 to 10 ; in Australia from 8 to 10 . It is likely that, in these last two cases at least, a part of the increase is due merely to more active occupation of fresh lands as well as to the use of more suitable varieties of seed, and the effect of improvements in methods of cultivation alone is more apparent in the older countries. During the same period the average yield increased in the United Kingdom from 28 to 32 bushels, in France from 17 to 20 , Holland 27 to 33 , Belgium 30 to 35 , and it is most marked in the German Empire, for which the figures are 19 and 29.

In another important paper ${ }^{1}$ Dr. Unstead has shown that the production of wheat in North America may still, in all likelihood, be very largely increased by merely increasing the area under cultivation, and the reasoning by which he justifies this conclusion certainly holds good over large districts elsewhere. It is of course impossible, in the present crude state of our knowledge of our own planet, to form any accurate estimate of the area which may, by the use of suitable seeds or otherwise, become available for extensive cultivation. But $I$ think it is clear that the available proportion of the total supply from "extensive" sources has reached, or almost reached, its maximum, and that we must depend more and more upon intensive farming, with its greater demands for labour.

The average total area under wheat is estimated by Dr. Unstead as 192 million acres for 1881-90, 211 million acres for 1891-1900, and 242 million acres for 1901-10. Making the guess, for we can make nothing better, that this area may be increased to 300 million acres, and that under ordinary agriculture the average yield may eventually be increased to 20 bushels over the whole, we get an average harvest of 6000 million bushels of wheat. The average wheat-eater consumes, according to Sir William Crookes' figures, about four and a half bushels per annum; but the amount tends to increase. It is as much (according to Dr. Unstead) as six bushels in the United Kingdom and eight bushels in France. Let us take the British figure, and it appears that on a liberal estimate

1 Geographical Journal, April and May 1912. 
the earth may in the end be able to feed permanently 1000 million wheat-eaters. If prophecies based on population statistics are trustworthy, the crisis will be upon us before the end of this century. After that we must either depend upon some substitute to reduce the consumption per head of the staple foodstuff, or we must take to intensive farming of the most strenuous sort, absorbing enormous quantities of labour and introducing, sooner or later, serious difficulties connected with plant-food. We leave the possibility of diminishing the rate of increase in the number of bread-eaters out of account.

We gather, then, that the estimates formed in 1898 are in the main correct, and the wheat problem must become one of urgency at no distant date, although actual shortage of food is a long way off. What is of more immediate significance to the geographer is the element of change, of return to earlier conditions, which is emerging even at the present time. If we admit, as I think we must do, that the days of increase of extensive farming on new land are drawing to a close, then we admit that the assignment of special areas for the production of the food-supply of other distant areas is also coming to its end. The opening up of such areas, in which a sparse population produces food in quantities largely in excess of its own needs, has been the characteristic of our time, but it must give place to a more uniform distribution of things, tending always to the condition of a moderately dense population, more uniformly distributed over large areas, capable of providing the increased labour necessary for the higher type of cultivation, and selfsupporting in respect of grain-food at least. We observe in passing that the colonial system of our time only became possible on the large scale with the invention of the steam locomotive, and that the introduction of railway systems in the appropriate regions, and the first tapping of nearly all such regions on the globe, has taken less than a century.

Concentration in special areas of settlement, formerly chiefly effected for military reasons, has in modern times been determined more and more by the distribution of supplies of energy. The position of the manufacturing district is primarily determined by the supply of coal. Other forms of energy are, no doubt, available, but, as Sir William Ramsay showed in his Presidential Address at the Portsmouth meeting in 1911, we must in all probability look to coal as being the chief permanent source.

In the early days of manufacturing industries the main difficulties arose from defective land transport. The first growth of the industrial system, therefore, took place where sea transport was relatively easy; raw material produced in a region near a coast was carried to a coalfield also near a coast, just as in the times when military power was chiefly a matter of "natural defences," the centre of power and the food-producing colony had to be mutually accessible. Hence the Atlantic took the place of the Mediterranean, Great Britain eventually succeeded Rome, and eastern North America became the counterpart of Northern Africa. It is to this, perhaps more than to anything else, that we in Britain owe our tremendous start amongst the industrial nations, and we observe that we used it to provide less favoured nations with the means of improving 
their system of land transport, as well as actually to manufacture imported raw material and redistribute the products.

But there is, of course, this difference between the supply of foodstuff (or even military power) and mechanical energy, that in the case of coal at least it is necessary to live entirely upon capital ; the storing up of energy in new coalfields goes on so slowly in comparison with our rate of expenditure that it may be altogether neglected. Now in this country we began to use coal on a large scale a little more than a century ago. Our present yearly consumption is of the order of 300 millions of tons, and it is computed ${ }^{1}$ that at the present rate of increase "the whole of our available supply will be exhausted in 170 jears." With regard to the rest of the world we cannot, from lack of data, make even the broad assumptions that were possible in the case of wheat supply, and for that and other reasons it is. therefore impossible even to guess at the time which must elapse before a universal dearth of coal becomes imminent; it is perhaps sufficient to observe that to the best of our knowledge and belief one of the world's largest groups of coal. fields (our own) is not likely to last three centuries in all.

Here again the present interest lies rather in the phases of change which are actually with us. During the first stages of the manufacturing period energy in any form was exceedingly difficult to transport, and this led to intense concentration. Coal was taken from the most accessible coalfield and used, as far as possible, on the spot. It was chiefly converted into mechanical energy by means of the steam engine, an extremely wasteful apparatus in small units, hence still further concentration; thus the steam engine is responsible in part for the factory system in its worst aspect. The less accessible coalfields were neglected. Also, the only other really available source of energywater-power-remained unused, because the difficulties in the way of utilising movements of large quantities of water through small vertical distances (as in tidal movements) are enormous; the only easily applied source occurs where comparatively small quantities of water fall through considerable vertical distances, as in the case" of waterfalls. But, arising from the geographical conditions, waterfalls (with rare exceptions such as Niagara) occur in the "torrential" part of the typical river-course, perhaps far from the sea, almost certainly in a region too broken in surface to allow of easy communication or even of industrial settlement of any kind.

However accessible a coalfield may be to begin with, it sooner or later becomes inaccessible in another way, as the coal near the surface is exhausted and the workings get deeper. No doubt the evil day is postponed for a time by improvements in methods of mining-a sort of intensive cultivation-but as we can put nothing back the end must be the same, and successful competition with more remote but more superficial deposits becomes impossible. And every improvement in land transport favours the geographically less accessible coalfields.

From this point of view it is impossible to overestimate the import- 
ance of what is to all intents and purposes a new departure of the same order of magnitude as the discovery of the art of smelting iron with coal, or the invention of the steam engine, or of the steam locomotive. I mean the conversion of energy into electricity, and its transmission in that form (at small cost and with small loss) through great distances. First we have the immediately increased availability of the great sources of cheap power in waterfalls. The energy may be transmitted through comparatively small distances and converted into heat in the electric furnace, making it possible to smelt economically the most refractory ores, as those of aluminium, and converting such unlikely places as the coast of Norway or the West Highlands of Scotland into manufacturing districts. Or it may be transmitted through greater distances to regions producing quantities of raw materials, distributed there widespread to manufacturing centres, and re-converted into mechanical energy. The Plain of Lombardy produces raw material in abundance, but Italy has no coal supply. The waterfalls of the Alps yield much energy, and this transmitted in the form of electricity, in some cases for great distances, is converting Northern Italy into one of the world's great industrial regions. Chisholm gives an estimate of a possible supply of power amounting to 3,000,000 horse-power, and says that of this about onetenth was already being utilised in the year 1900 .

But assuming again, with Sir William Ramsay, that coal must continue to be the chief source of energy, it is clear that the question of accessibility now wears an entirely different aspect. It is not altogether beyond reason to imagine that the necessity for mining, as such, might entirely disappear, the coal being burnt in situ and energy converted directly into electricity. In this way some coalfields might conceivably be exhausted to their last pound without serious increase in the cost of getting. But for the present it is enough to note that, however inaccessible any coalfield may be from supplies of raw material, it is only necessary to establish generating stations at the pit's mouth and transport the energy to where it can be used. One may imagine, for example, vast manufactures carried on in what are now the immense agricultural regions of China, worked by power supplied from the great coal deposits of Shan-si.

There is, however, another peculiarity of electrical power which will exercise increasing influence upon the geographical distribution of industries. The small electric motor is a much more efficient apparatus than the small steam engine. We are, accordingly, already becoming familiar with the great factory in which, instead of all tools being huddled together to save loss through shafting and belting, and all kept running all the time, whether busy or not (because the main engine must be run), each tool stands by itself and is worked by its own motor, and that only when it is wanted. Another of the causes of concentration of manufacturing industry is therefore reduced in importance. We may expect to see the effects of this becoming more and moremarked as time'goes on, and other forces working towards uniform dis-: tribution make themselves more felt.

The points to be emphasised so far, then, are, first, that the time 
when the available areas whence food supply, as represented by wheat, is derived are likely to be taxed to their full capacity within a period of about the same length as that during which the modern colonial system has been developing in the past; secondly, that cheap supplies of energy may continue for a longer time, although eventually they must greatly diminish; and, thirdly, there must begin in the near future a great equalisation in the distribution of population. This equalisation must arise from a number of causes. More intensive cultivation will increase the amount of labour required in agriculture, and there will be less difference in the cost of production and yield due to differences of soil and climate. Manufacturing industries will be more uniformly distributed, because energy, obtained from a larger number of sources in the less accessible places, will be distributed over an increased number of centres. The distinction between agricultural and industrial regions will tend to become less and less clearly marked, and will eventually almost disappear in many parts of the world.

The effect of this upon the third element is of first-rate importance. It is clear that as the process of equalisation goes on the relative amount of long-distance transport will diminish, for each district will tend more and more to produce its own supply of staple food and carry on its own principal manufactures. This result will naturally be most marked in what we may call the "east-and-west" transport, for as climatic controls primarily follow the parallels of latitude, the great quantitative trade, the flow of food-stuffs and manufactured articles to and fro between peoples of like habits and modes of life, runs primarily east and west. Thus the transcontinental functions of the great North American and Eurasian railways, the east-and-west systems of the inland waterways of the two continents, and the connecting-links furnished by the great ocean ferries, must become of relatively less importance.

The various stages may be represented, perhaps, in some such manner as this. If $I$ is the cost of producing a thing locally at a place $A$ by intensive cultivation or what corresponds to it, if $E$ is the cost of producing the same thing at a distant place $B$, and $T$ the cost of transporting it to $A$, then at $A$ we may at some point of time have a more or less close approximation to

$$
\mathbf{I}=\mathbf{E}+\mathbf{T} \text {. }
$$

We have seen that in this country, for example, $I$ has been greater than $\mathbf{E}+\mathbf{T}$ for wheat ever since, say, the introduction of railways in North America, that the excess tends steadily to diminish, and that however much it may be possible to reduce $\mathbf{T}$ either by devising cheaper modes of transport or by shortening the distance through which wheat is transported, $\mathbf{E}+\mathbf{T}$ must become greater than $\mathbf{I}$, and it will pay us to grow all or most of our own wheat. Conversely, in the seventies of last century I was greater than $\mathbf{E}+\mathbf{T}$ in North America and Germany for such things as steel rails and rolling-stock, which we in this country were cultivating "extensively" at the time on more accessible coalfields, with more skilled labour and better organisation than could be found elsewhere. In many cases the positions are now, as we know, reversed, but geographically I must win all round in the long run. 
In the case of transport between points in different latitudes, the conditions are, of course, altogether dissimilar, for in this case commodities consist of foodstuffs, or raw materials, or manufactured articles, which may be termed luxuries, in the sense that their use is scarcely known until cheap transport makes them easily accessible, when they rapidly become "necessaries of life." Of these the most familiar examples are tea, coffee, cocoa, and bananas, indiarubber and manufactured cotton goods. There is here, of course, always the possibility that wheat as a staple might be replaced by a foodstuff produced in the tropics, and it would be extremely interesting to study the geographical consequences of such an event as one-half of the surface of the earth suddenly coming to help in feeding the two quarters on either side; but for many reasons, which I need not go into here, such a consummation is exceedingly unlikely. What seems more probable is that the trade between different latitudes will continue to be characterised specially by its variety, the variety doubtless increasing, and the quantity increasing in still larger measure. The chief modification in the future may perhaps be looked for in the occasional transference of manufactures of raw materials produced in the tropics to places within the tropics, especially when the manufactured article is itself largely consumed near regions of production. The necessary condition here is a region, such as, e.g., the monsoon region, in which there is sufficient variation in the seasons to make the native population laborious; for then, and apparently only then, is it possible to secure sufficient industry and skill by training, and therefore to be able to yield to the ever-growing pressure in more temperate latitudes due to increased cost of labour. The best examples of this to-day are probably the familiar ones of cotton and jute manufacture in India. With certain limitations, manufacturing trade of this kind is, however, likely to continue between temperate and strictly tropical regions, where the climate is so uniform throughout the year that the native has no incentive to work. There the collection of the raw material is as much as, or even more than can be looked for-as in the case of mahogany or wild rubber. Where raw material has to be cultivated-as cotton, cultivated rubber, ete.- the raw material has to be produced in regions more of the monsoon type, but it will probablyperhaps as much for economic as geographical reasons-be manufactured at some centre in the temperate zones, and the finished product transported thence, when necessary, to the point of consumption in the tropics.

We are here, however, specially liable to grave disturbances of distribution arising from invention of new machinery or' new chemical methods; one need only mention the production of sugar or indigo. Another aspect of this which is not without importance may perhaps be referred to here, although it means the transference of certain industries to more accessible regions merely, rather than a definite change of such an element as latitude. I have in mind the sudden conversion of an industry in which much labour is expended on a small amount of raw material into one where much raw material is consumed, and by the application of power-driven machinery the labour required is greatly 
diminished. One remembers when a fifty-shilling Swiss watch, although then still by tradition regarded as sufficiently valuable to deserve enclosure in a case constructed of a precious metal, was considered a marvel of cheapness. American machine-made watches, produced by the ton, are now encased in the baser metals and sold at some five shillings each, and the watch-making industry has ceased to be specially suited to mountainous districts.

In considering the differences which seem likely to arise in what we may call the regional pressures of one kind and another, pressures which are relieved or adjusted by and along certain lines of transport, I have made a primary distinction between "east-and-west" and "north-andsouth" types, because both in matters of food-supply and in the modes of life which control the nature of the demand for manufactured articles climate is eventually the dominant factor; and, as I have said, climate varies primarily with latitude. This is true specially of atmospheric temperature; but temperature varies also with altitude, or height above the level of the sea. To a less extent rainfall, the other great element of climate, varies with altitude, but the variation is much more irregular. More important in this case is the influence of the distribution of land and sea, and more especially the configuration of the land surface, the tendency here being sometimes to strengthen the latitude effect where a continuous ridge is interposed, as in Asia, practically cutting off "northand-south" communication altogether along a certain line, emphasising the parallel-strip arrangement running east and west to the north of the line, and inducing the quite special conditions of the monsoon region to the south of it. We may contrast this with the effect of a " north-andsouth" structure, which (in temperate latitudes especially) tends to swing what we may call the regional lines round till they cross the parallels of latitude obliquely. This is typically illustrated in North America, where the angle is locally sometimes nearly a right angle. It follows, therefore, that the contrast of "east-and-west" and " north-and-south" lines, which I have here used for purposes of illustration, is necessarily extremely crude, and one of the most pressing duties of geographers at the present moment is to elaborate a more satisfactory method of classification. I am very glad that we are to have a discussion on "Natural Regions" at one of our sederunts. Perhaps I may be permitted to express the hope that we shall concern ourselves with the types of region we want, their structure or "grain," and their relative positions, rather than with the precise delimitation of their boundaries, to which I think we have sometimes been inclined, for educational purposes, to give a little too much attention.

Before leaving this I should like to add, speaking still in terms of "east-and-west" and "north-and-south," one word more about the essentially east-and-west structure of the Old World. I have already. referred to the great central axis of Asia. This axis is prolonged westward through Europe, but it is cut through and broken to such an extent that we may include the Mediterranean region with the area lying further north, to which indeed it geographically belongs, in any discussion of this sort. But the Mediterranean region is bounded on the other 
side by the Sahara, and none of our modern inventions facilitating transport has made any impression upon the dry desert; nor does it seem likely that such a desert will ever become a less formidable barrier than a great mountain mass or range. We may conclude, then, that in so far as the Old World is concerned, the "north-and-south" transport can never be carried on as freely as it may in the New, but only through certain weak points, or "round the ends," i.e. by sea. It may be further pointed out that the land areas in the southern hemisphere are so narrow ' that they will scarcely enter into the "east-and-west" category at allothe transcontinental railway as understoud in the northern hemisphere canOnot exist; it is scarcely a pioneer system, but rather comes into existence was a later by-product of local east-and-west lines, as in Africa.

These geographical facts must exercise a profound influence upon the afuture of the British Isles. Trade south of the great dividing line must -always be to a large extent of the "north-and-south" type, and the British Isles stand practically at the western end of the great natural Obarrier. From their position the British Isles will always be a centre of ت̈immense importance in entrepôt trade, importing commodities from "south" cand distributing "east and west," and similarly in the reverse direction. -This movement will be permanent, and will increase in volume long Fafter the present type of purely "east-and-west" trade has become Trelatively less important than it is now, and long after the British Isles Thave ceased to have any of the special advantages for manufacturing Findustries which are due to their own resources either in the way of Eenergy or of raw material. We can well imagine, however, that this per$\overline{\bar{\theta}}$ manent advantage of position will react favourably, if indirectly, upon certain types of our manufactures, at least for a very long time to come.

Reverting briefly to the equalisation of the distribution of population Fin the wheat-producing areas and the causes which are now at work in this direction, it is interesting to inquire how geographical conditions are likely to influence this on the smaller scale. We may suppose that the production of staple foodstuffs must always be more uniformly disEtributed than the manufacture of raw materials, or the production of the Eraw materials themselves, for the most important raw materials of vegeztable origin (as cotton, rubber, etc.) demand special climatic conditions, Jand, apart from the distribution of energy, manufacturing industries are E्]strongly influenced by the distribution of mineral deposits, providing Ometals for machinery, and so on. It may, however, be remarked that the useful metals, such as iron, are widely distributed in or near regions owhich are not as a rule unfavourable to agriculture. Nevertheless, the fact remains that while a more uniform distribution is necessary and inevitable in the case of agriculture, many of the conditions of industrial and social life are in favour of concentration; the electrical transmission of energy removes, in whole or in part, only one or two of the centripetal forces. The general result might be an approximation to the conditions occurring in many parts of the mousoon areas-a number of fairly large towns pretty evenly distributed over a given agricultural area, and each drawing its main food supplies from the region surrounding it. The positions of such towns would be determined much more by industrial 
conditions, and less by military conditions, than in the past (military power being in these days mobile, and not fixed); but the result would on a larger scale be of the same type as was developed in the central counties of England, which, as Mackinder has pointed out, are of almost equal size and take the name of the county town. Concentration within the towns would, of course, be less severe than in the early days of manufacturing industry. Each town would require a very elaborate and 'highly organised system of local transport, touching all points of its agricultural area, in addition to lines of communication with other towns and with the great "north-and-south" lines of world-wide commerce, but these outside lines would be relatively of less importance than they are now. We note that the more perfect the system of local transport the less the need for points of intermediate exchange. The village and the local market-town will be "sleepy" or decadent as they are now, but for a different reason; the symptoms are at present visible mainly because the country round about such local centres is overwhelmed by the great lines of transport which pass through them; they will survive for a time through inertia and the ease of foreign investment of capital. The effect of this influence is already apparent since the advent of the "commercial motor," but up to the present it has been more in the direction of distributing from the towns than collecting to them, producing a kind of "suburbanisation" which throws things still further out of balance. The importance of the road motor in relation to the future development of the food-producing area is incalculable. It has long been clear that the railway of the type required for the great through lines of fast transport is ill-adapted for the detailed work of a small district, and the "light" railway solves little and introduces many complications. The problem of determining the direction and capacity of a system of roads adequate to any particular region is at this stage one of extraordinary difficulty; experiments are exceedingly costly, and we have as yet little experience of a satisfactory kind to guide us. The geographer, if he will, can here be of considerable service to the engineer.

In the same connexion, the development of the agricultural area supplying an industrial centre offers many difficult problems in relation to what may be called accessory products, more especially those of a perishable nature, such as meat and milk. In the case of meat the present position is that much land which may eventually become available for grain crops is used for grazing, or cattle are fed on some grain; like maize, which is difficult to transport or is not satisfactory for breadmaking. The meat is then temporarily deprived of its perishable property by refrigeration, and does not suffer in transport. Modern refrigerating machinery is elaborate and complicated, and more suited to use on board ship than on any kind of land transport. Hence the most convenient. regions for producing meat for export are those near the sea-coast, such as occur in the Argentine or the Canterbury plains of New Zealand. The case is similar to that of the "accessible" coalfield. Possibly the preserving processes may be simplified and cheapened, making overland transport easier, but the fact that it usually takes a good deal of land to produce a comparatively small quantity of meat will make the difficulty 
greater as land becomes more valuable. Cow's milk, which in modern times has become a "necessary of life" in most parts of the civilised world, is in much the same category as meat, except that difficulties of preservation, and therefore of transport, are even greater. That the problem has not become acute is largely due to the growth of the longtransport system available for wheat, which has enabled land round the great centres of population to be devoted to dairy produce. If we are right in supposing that this state of things cannot be permanent the difficulty of milk supply must increase, although relieved somewhat by 6 the less intense concentration in the towns; unless, as seems not unlikely, ¿ $a$ wholly successful method of permanent preservation is devised.

In determining the positions of the main centres, or rather, in subdividing the larger areas for the distribution of towns with their supporting $\sigma$ and dependent districts, water supply must be one of the chief factors $\infty$ in the future, as it has been in the past; and in the case of industrial centres the quality as well as the quantity of water has to be considered. ปे A fundamental division here would probably be into districts having a * natural local supply, probably of hard water, and districts in which the o supply must be obtained from a distance. In the latter case engineering works of great magnitude must often be involved, and the question of total resources available in one district for the supply of another must $\exists$ be much more fully investigated than it has been. In many cases, as in If this country, the protection of such resources pending investigation is already much needed. It is worth noting that the question may often $\&$ be closely related to the development and transmission of electrical energy from waterfalls, and the two problems might in such cases be dealt with together. Much may be learned about the relation of water supply to distribution of population from a study of history, and a more active prosecution of combined historical and geographical research would, I believe, furnish useful material in this connexion, besides throwing interesting light on many historical questions.

Continued exchange of the "north-and-south" type and at least a part of that described as "east-and-west" gives permanence to a certain number of points where, so far as can be seen, there must always be a change in the mode of transport. It is not likely that we shall have heavy freight-carrying monsters in the air for a long time to come, and until we have the aerial "tramp" transport must be effected on the surfaces of land and sea. However much we may improve and cheapen land transport it cannot in the nature of things become as cheap as transport by sea. For on land the essential idea is always that of a prepared road of some kind, and, as Chisholm has pointed out, no road can carry more than a certain amount; traffic beyond a certain quantity constantly requires the construction of new roads. It follows, then, that no device is likely to provide transport indifferently over land and sea, and the seaport has in consequence inherent elements of permanence. Improved and cheapened land transport increases the economy arising from the employment of large ships rather than small ones, for not only does transport inland become relatively more important, but distribution along a coast from one large seaport becomes as easy as from a number of 
small coastal towns. Hence the conditions are in favour of the growth of a comparatively small number of immense seaport cities like London and New York, in which there must be great concentration not merely of work directly connected with shipping, but of commercial and financial interests of all sorts. The seaport is, in fact, the type of great city which seems likely to increase continually in size, and provision for its needs cannot in general be made from the region immediately surrounding it, as in the case of towns of other kinds. In special cases there is also, no doubt, permanent need of large inland centres of the type of the "railway creation," but under severe geographic control these must depend very much on the nature and efficiency of the systems of land transport. It is not too much to say (for we possess some evidence of it. already) that the number of distinct geographical causes which give rise to the establishment and maintenance of individual great cities is steadily diminishing, but that the large seaport is a permanent and increasing necessity. It follows that aggregations of the type of London and Liverpool, Glasgow and Belfast will always be amongst the chief things to be reckoned with in these islands, irrespective of local coal supply or accessory manufacturing industries, which may decay through exhaustion.

I have attempted in what precedes to draw attention once more to certain matters for which it seems strangely difficult to get a hearing. What it amounts to is this, that as far as our information goes the development of the steamship and the railway, and the universal introduction of machinery which has arisen from it, have so increased the demand made by man upon the earth's resources that in less than a century they will have become fully taxed. When colonisation and settlement in a new country proceeded slowly and laboriously, extending centrifugally from one or two favourable spots on the coast, it took a matter of four centuries to open up a region the size of England. Now we do as much for a continent like North America in about as many decades. In the first case it was not worth troubling about the exhaustion of resources, for they were scarcely more than touched, and even if they were exhausted there were other whole continents to conquer. But now, so far as our information goes, we are already making serious inroads upon the resources of the whole earth. One has no desire to sound an unduly alarmist note, or to suggest that we are in imminent danger of starvation, but surely it would be well, even on the suspicion, to see if our information is adequate and reliable and if our conclusions are correct; and not merely to drift in a manner which was justifiable enough in Saxon times, but which, at the rate things are going now, may land us unexpectedly in difficulties of appalling magnitude.

What is wanted is that we should seriously address ourselves to a stocktaking of our resources. A beginning has been made with a great map on the scale of one to a million, but that is not sufficient; we should vigorously proceed with the collection and discussion of geographical data of all kinds, so that the major natural distributions shall be adequately known, and not merely those parts which commend themselves, for one reason or another, to special national or private enterprises. The method of 
Government survey, employed in most civilised countries for the construction of maps, the examination of geological structure or the observation of weather and climate, is satisfactory as far as it goes, but it should go further, and be made to include such things as vegetation, water supply, supplies of energy of all kinds, and, what is quite as important, the bearings of one element upon others under different conditions. Much, if not most, of the work of collecting data would naturally be done as it is now by experts in the special branches of knowledge, but it is essential that there should be a definite plan of a geographical survey as a whole, in order that the regional or distributional aspect should never be lost sight of. I may venture to suggest that a committee formed jointly by the great national geographical societies, or by the International Geographical Congress, might be entrusted with the work of formulating some such uniform plan and suggesting practicable methods of carrying it out. It should not be impossible to secure international co-operation, for there is no need to investigate too closely the secrets of any one's particular private vineyard--it is merely a question of doing thoroughly and systematically what is already done in some regions, sometimes thoroughly, but not systematically. We should thus arrive eventually at uniform methods of stock-taking, and the actual operations could be carried on as opportunity offered and indifference or opposition was overcome by the increasing need for information. Eventually we shall find that "country-planning" will become as important as townplanning, but it will be a more complex business, and it will not be possible to get the facts together in a hurry. And in the meanwhile increased geographical knowledge will yield scientific results of much significance about such matters as distribution of populations and industries, and the degree of adjustment to new conditions which occurs* or is possible in different regions and amongst different peoples. Primary surveys on the large scale are specially important in new regions, but the best methods of developing such areas and of adjusting distributions in old areas to new economic conditions are to be discovered by extending the detailed surveys of small districts. An example of how this may be done has been given by Dr. Mill in his Fragment of the Geography of Sussex. Dr. Mill's methods have been successfully applied by individual investigators to other districts, but a definitely organised system, marked out on a carefully matured uniform plan, is necessary if the results are to be fully comparable. The schools of geography in this country have already done a good deal of local geography of this type, and could give much valuable assistance if the work were organised beforehand on an adequate scale.

But in whatever way and on whatever scale the work is done, it must be clearly understood that no partial study from the physical, or biological, or historical, or economic point of view will ever suffice. The urgent matters are questions of distribution upon the surface of the earth, and their elucidation is not the special business of the physicist, or the biologist, or the historian, or the economist, but of the geographer. 